\title{
Water Resources Observation and Large-scale Model Estimation in Forested Areas in Mekong River Basin
}

\author{
Akira SHIMIZU ${ }^{1 *}$, Masakazu SUZUKI ${ }^{3}$, Shinji SAWANO ${ }^{4}$, Naoki KABEYA ${ }^{1}$, \\ Tatsuhiko NOBUHIRO ${ }^{2}$, Koji TAMAI ${ }^{2}$, Yoshio TSUBOYAMA ${ }^{2}$, Sophal CHANN ${ }^{5}$ \\ and Nang KETH ${ }^{5}$
}

1 Kyushu Research Center, Forestry and Forest Products Research Institute (FFPRI)

(Kumamoto 860-0862, Japan)

2 FFPRI (Tsukuba, Ibaraki 305-8687, Japan)

3 Graduate School of Agricultural and Life Sciences, The University of Tokyo

(Bunkyo, Tokyo 113-8657, Japan)

4 National Institute for Agro-Environmental Sciences (Tsukuba, Ibaraki 305-8604, Japan)

5 Forestry Administration, Forest and Wildlife Science Research Institute

(Phnom Penh, Cambodia)

\begin{abstract}
In this paper, we have measured many meteorological elements associated with evapotranspiration using a 60-m-high meteorological observation tower, runoff and precipitation of broad-leaf forest watersheds in the Kampong Thom Province of central Cambodia. Moreover, an interception plot was established for calculating the rainfall interception ratio by forest coverage close to the tower. Analyzing many kinds of observed data, we evaluated Stung Chinit watershed, which had the largest drainage area and an annual loss of $\sim 1200 \mathrm{~mm}$. This value was in agreement with annual evapotranspiration estimated in 2004 by the Bowen ratio energy balance method. The annual canopy interception rate, which is one of the most important hydrological factors in the forest, was approximately $15 \%$. Also, the rainfall interception process was reproduced well according to the multilayer model. The available renewable freshwater resources in forested areas of the Mekong River basin were estimated by modeling. Annual available renewable freshwater resources in forested areas of the Mekong ranged from 300 to $2200 \mathrm{~mm} /$ year. The mountainous area of west Cambodia had vast renewable freshwater resources, and almost all regions had $500 \mathrm{~mm} /$ year. This result mostly corresponded to the amount of water resources in the largest evergreen forest experimental watershed including several small watersheds in central Cambodia.
\end{abstract}

Discipline: Forestry and forest products

Additional key words: available renewable freshwater resources, canopy interception, experimental watershed, large-scale model, rainfall-runoff observation, water budget

\section{Introduction}

The Mekong River is an international river and passes through a range of climatic zones. This river originates on the Tibetan Plateau and flows into the South China Sea after passing through several countries including Myanmar, Laos, Thailand, Cambodia, and Vietnam. In the Mekong River basin, the increase in farming to support a rapidly growing population has led to a dramatic reduction in forest area. The incidence of illegal logging and wood collection is also increasing throughout the entire Asian monsoon area, including the Indochinese Peninsula. According to Cambodian government statistics ${ }^{9}$, the proportion of forested area in Cambodia declined from $74 \%$ in the 1970 s to $58 \%$ in 1997 . The loss and degradation of forest lands may cause substantial changes in the water cycle of forested watersheds and can lead to frequent occurrences of floods or water shortages.

On the other hand, the area covered by forests in Cambodia remains high compared with that in adjacent countries now. The relatively well-preserved state of Cambodian forests indicates the pivotal role they play with regard to the water cycle in Cambodia and surrounding

*Corresponding author : e-mail akiraxx@affrc.go.jp

Received 25 March 2008; accepted 22 July 2009. 
regions. Moreover, there is very little published information on forests in Cambodia in the former. Clearly, there is a need to study the forests in the Mekong basin in greater detail, considering the influence that this river system can have on the region as a whole.

In this paper, the condition of the water resources in the forest area of the Mekong River basin is presented based on a consideration using hydrological observation and a large-scale model. We installed several forest experimental watersheds in the Kampong Thom Province of central Cambodia as a typical area of a forest zone. We accumulated base information on actual water balance conditions from observations of rainfall runoff processes in these experimental forest watersheds. On the other hand, the large-scale potential water-resources model for the whole Mekong River basin is developed, to these observations. The precision of the model was investigated and availability was examined by confirmation according to observational data, or comparison with other models. Available renewable freshwater resources in a forest watershed were estimated with this model integrating some information such as satellite information. The estimated available renewable freshwater resources were provided as information for administrative policy-making of forest management or input to the agricultural area, which is a downstream region, etc.

\section{Study site, observation methods, and application model}

\section{(1) Forest experimental watersheds and observation method in central part of Cambodia}

The research group established four experimental watersheds in central Cambodia. To elucidate the water cycle in forested areas of the Mekong River basin, we investigated water budgets and flow regimes for the forested watershed sites using year-round observation data. The four experimental watersheds were in Kampong Thom Province, central Cambodia (Fig. 1). The O Toek Loork (OTL), O Thom I (OT1), O Thom II (OT2), and Stung Chinit (CT) watersheds drain areas of $4 \mathrm{~km}^{2}, 137 \mathrm{~km}^{2}$, $126 \mathrm{~km}^{2}$, and $3659 \mathrm{~km}^{2}$, respectively, and range in altitude from 89 to $142 \mathrm{~m}, 46$ to $273 \mathrm{~m}, 19$ to $74 \mathrm{~m}$, and 19 to $653 \mathrm{~m}$, respectively. Although all four watersheds have relatively flat topography, O Toek Loork and O Thom II are especially flat, with ranges in altitude of only approxi-

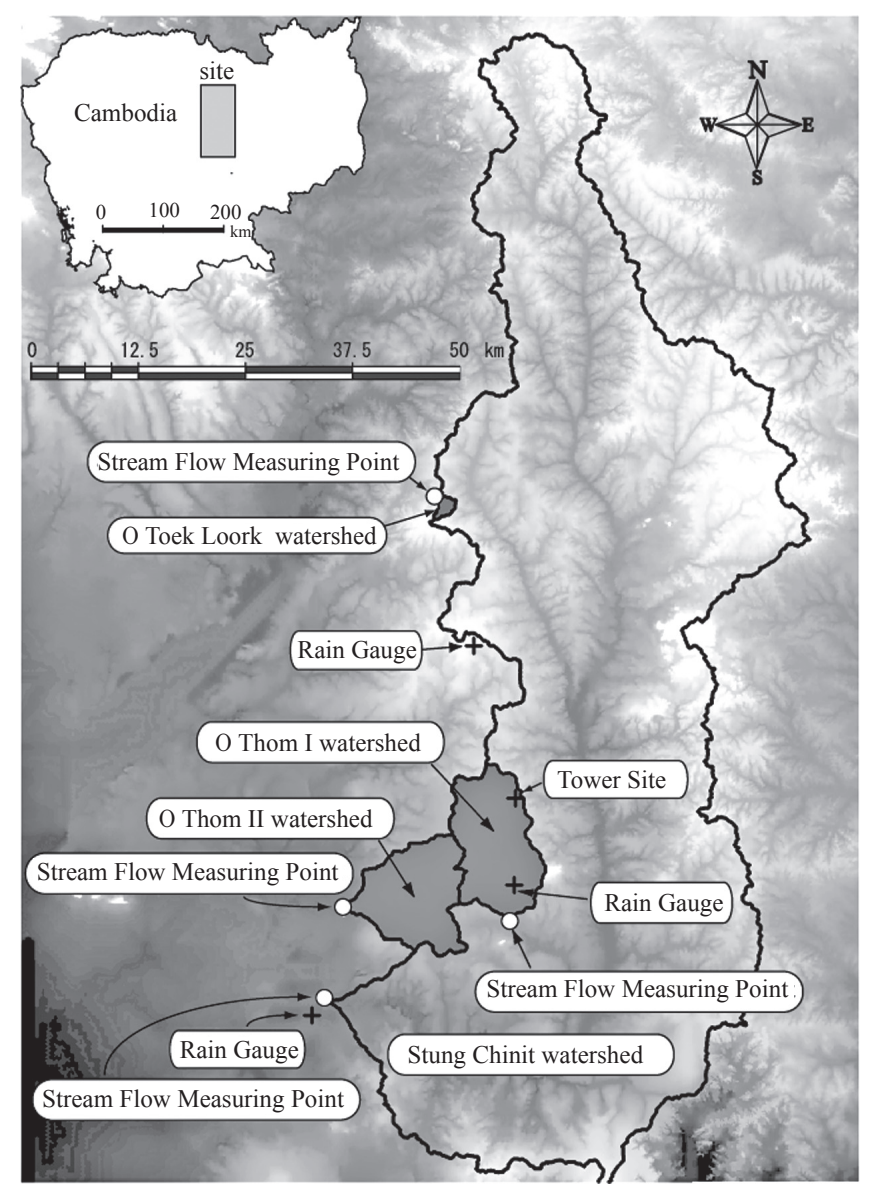

Fig. 1. Location of four experimental watersheds in Kampong Thom, Cambodia 
mately $50 \mathrm{~m}$. The climate is sub-tropical and governed by two monsoons, the cool, dry northeastern monsoon from November to March and the humid southwestern monsoon from May to October. Streams at the water-level observation points of the four forest watersheds flow perennially, even though little rain falls from December to February. The geology of O Toek Loork, O Thom I, and O Thom II watersheds is quaternary sediment. Quaternary sediment predominates in Stung Chinit, but shale occurs in the northern part of the watershed and basalt in the southern part. The soil type changes with vegetation type; Acrisols occur beneath the evergreen broadleaf forest, which is the dominant vegetation type of this area ${ }^{11}$.

In terms of the land cover of the four experimental watersheds, the percentage of forested area, including evergreen broadleaved forest, deciduous forest, bamboo and secondary forest, and mixed forest, in three watersheds (excluding O Thom II) was more than $90 \%$ (Fig. 2). Most forested areas were composed of evergreen broadleaved forest. O Thom II had a lower percentage of forest (as low as $55 \%$ ) and a relatively high percentage of grassland and shrubland (approximately 44\%), with the composition of vegetation types differing slightly from that in the other watersheds.

The amount of water loss, an important factor in water balance analysis, was studied continuously in O Thom I experimental watershed located in central Cambodia.
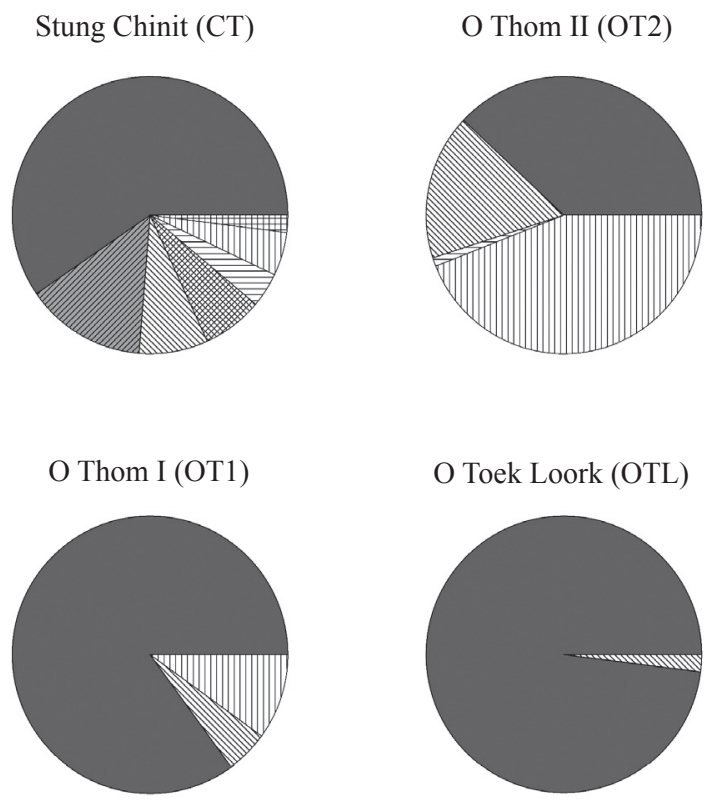

Fig. 2. Coverage ratio in four experimental watersheds

: Evergreen broadleaf forest, 펮 : Deciduous forest, : Bamboo and secondary forests, : Mixed forest from evergreen $\&$ deciduous species,

$\rightleftharpoons$ : Field crop, $\mathbb{m}$ m : Shrublands \& grasslands, 曲曲 : Paddy field.
Vegetation of the experimental watershed consisted of evergreen broadleaved trees such as Dipterocarp species. A $60 \mathrm{~m}$ tall meteorological observation tower and a canopy interception plot $(25 \times 25 \mathrm{~m})$ were set up in the northeast part of the watershed $\left(12^{\circ} 44^{\prime} \mathrm{N}, 105^{\circ} 28^{\prime} \mathrm{E}\right)$. The topography near the tower and interception plot was very flat. Evapotranspiration, which is the main element of water loss from the forested area, was estimated from temperature and water vapor pressure profiles observed at the meteorological observation tower, using the Bowen ratio energy balance (BREB) method. The period of estimation of evapotranspiration was from November 2003 to October 2004. The relationships between rainfall, throughfall, and stem flow observed in the interception plot were analyzed and the amount of canopy interception was estimated. Moreover, a sensitivity analysis with a multilayer mode ${ }^{14}$ was conducted on throughfall measurements, and the relationship between canopy structure and other factors of canopy interception was examined.

\section{(2) Model estimation of available renewable \\ freshwater resources in forest areas of the Mekong River basin}

Elevation and gradient data were used to clarify topographical characteristics of the basin. The 30-arcsec digital elevation dataset GTOPO30 provided by the U.S. Geological Survey (USGS) was processed to yield gradient data. The MOD12Q1 dataset classified from the MODIS data using the University of Maryland method ${ }^{2}$ provided land cover data, including forest-type distributions. A model was developed that required monthly meteorological data to estimate evapotranspiration. Accordingly, we processed International Satellite Land Surface Climatology Project (ISLSCP) Initiative-1 data $^{8}$, which contained 6-hourly data with a spatial resolution of $1.0 \times 1.0$ degree for 1987 and 1988 , to obtain monthly meteorological data. We subsequently interpolated the temperature data to a 30 -arcsec

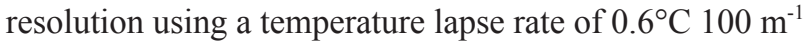
and the difference in elevation between points. Latent heat flux data from ISLSCP and GEWEX Asian Monsoon Experiment (GAME) reanalysis data ${ }^{15}$ with a spatial resolution of $2.5 \times 2.5$ degrees from April to October 1998 were used for model comparison.

A model was developed to estimate evapotranspiration in forested areas (E), a major component of the forest water budget. The model calculated transpiration $\left(\mathrm{E}_{\mathrm{t}}\right.$, including forest floor evaporation) and interception evaporation $\left(\mathrm{E}_{\mathrm{i}}\right)$ separately. Transpiration was calculated using the Priestley-Taylor (PT) equation ${ }^{12}$, and interception loss was assumed to be a fixed proportion of the rainfall. Evapotranspiration from forested areas was estimated using the following equation: 


$$
\begin{aligned}
E & =E_{t}+E_{i} \\
& =a \frac{\Delta}{\Delta+\gamma}-R_{n}+\beta P
\end{aligned}
$$

where $\alpha$ is the Priestley-Taylor constant, $\mathrm{Rn}$ is net radiation $\left(\mathrm{MJ} \mathrm{m}^{-2}\right), \Delta$ is the gradient of saturated vapor pressure with temperature, $\gamma$ is the psychrometric constant, $\beta$ is the interception ratio, and $\mathrm{P}$ is monthly precipitation. The PT equation required net radiation as input data; as only solar radiation data were available, we converted them to net radiation data. In forested areas, net radiation is 0.8 times the solar radiation ${ }^{6}$.

Available renewable freshwater resources (RFWR) constitute one index of the amount of freshwater resources. The index is expressed as follows:

$$
\mathrm{RFWR}=\mathrm{P}-\mathrm{E}
$$

We calculated the distribution of RFWR in forested areas of the Mekong River basin using this equation.

Table 1. Annual rainfall and discharge amounts in 2004 at each observation site

\begin{tabular}{crcc}
\hline \hline \multicolumn{2}{c}{ Annual rainfall $(\mathrm{mm} / \mathrm{y})$} & \multicolumn{2}{c}{ Annual discharge $(\mathrm{mm} / \mathrm{y})$} \\
\hline KD & $1,434.4$ & OTL & 93.1 \\
KA $^{*}$ & $>1,822.2$ & OT1 & 555.4 \\
TS** $^{*}$ & $>1,542.8$ & OT2 & 131.2 \\
BS & $1,565.4$ & CT & 362.6 \\
\hline
\end{tabular}

KD: Kbal Domrey, KA: Kampub Ambel, TS: Tower site, BS: Bak Snar Nursery, OTL: O Toek Loork, OT1: O Thom I, OT2: O Thom II, CT: Stung Chinit. * Period of lost data at KA: 14 August to 5 September. ** Period of lost data at TS: 1 January to 25 April.

\section{Results and discussion}

(1) Elucidation of forest catchment water budgets in the Mekong River basin

The annual rainfall in 2004 ranged from 1,434.4 to more than 1,822.2 $\mathrm{mm}$ at four observation sites (Bak Snar, the Tower Site, Kbal Domrey, and Kampub Ambel; Table 1). The annual rainfall at Bak Snar and Kbal Domrey was 1,565.4 and 1,434.4 mm, respectively. Periods of data loss occurred at Kampub Ambel from 14 August to 5 September and at the tower site from 1 January to 25 April. The annual rainfall at Kampub Ambel exceeded 1,822.2 $\mathrm{mm}$. There are two mountains $1 \mathrm{~km}$ north and $4 \mathrm{~km}$ west of Kampub Ambel, which may cause greater orographic rainfall at this site compared to the others. Annual rainfall was approximately 1,450 to $1,550 \mathrm{~mm}$, except at Kampub Ambel. This range is similar to annual rainfall for central Cambodia (around 1,500 $\mathrm{mm}$ ) reported by Hori ${ }^{4}$. The annual discharge in 2004 ranged from 93.1 to $555.4 \mathrm{~mm}$ in the four watersheds.

In O Toek Loork and O Thom II, which have very flat topography, annual discharge was 93.1 and $131.2 \mathrm{~mm}$, respectively; these amounts were smaller than those of the other two watersheds. O Thom I, which includes the high-rainfall Kampub Ambel site, had an annual discharge of $555.4 \mathrm{~mm}$, the largest of the four watersheds. Stung Chinit, which had the maximum drainage area, had an annual discharge of $362.6 \mathrm{~mm}$, which was within the range (93.1-555.4 mm) of the other smaller watersheds. Annual evapotranspiration in 2004 was estimated at approximately $1,150 \mathrm{~mm}$ by the BREB method at the tower site ${ }^{8}$. Thus, the entire Stung Chinit watershed can be considered to have a nearly closed water budget.

The seasonal variation in radiation energy components is the fundamental factor for analysis of the BREB

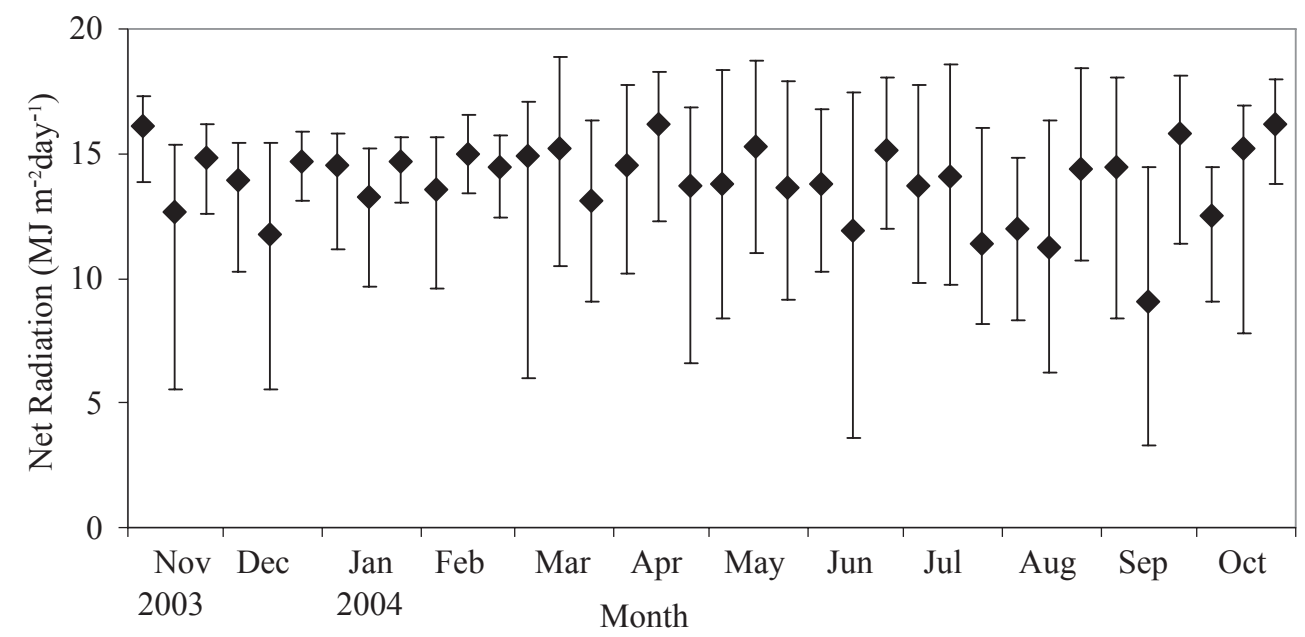

Fig. 3. Seasonal variation in net radiation 
method. Figure 3 shows the daytime amount of net radiation averaged every 10 days. Although radiation energy was affected by precipitation or cloud cover, the daytime amount of net radiation on fine days during the rainy season was similar to that during the dry season (the range of maximum values was 14 to $19 \mathrm{MJ} \mathrm{m}^{-2}$ day $^{-1}$ ). The occurrence of late evening rainfall was likely a factor.

Figure 4 shows seasonal variation in daily evapotranspiration rate with the BREB method (November 2003October 2004). The amount of year-round evapotranspiration during the observation period was estimated to be around 1,200 $\mathrm{mm}$. This result was similar to the water loss estimated from the water budget in the Stung Chinit watershed, which contains the $\mathrm{O}$ Thom I experimental watershed. A high evapotranspiration rate occurred at the beginning of the dry season (November 2003 and October 2004). The values obtained for evapotranspiration in this study are comparable to those reported from other stud- ies, $4.5 \mathrm{~mm}$ /day during the dry season in the northeastern region of Thailand ${ }^{3}$ and $4 \mathrm{~mm} /$ day for a tropical rain forest in Western Indonesia ${ }^{1}$. Moreover, a tendency of increased evapotranspiration was recognized from the end of February to the beginning of March 2004. Since a thick soil layer is distributed across the watershed and enough soil water subsists throughout the year, it was presumed that suppression of transpiration by lack of soil water did not occur even near the end of the dry season. Furthermore, the vapor pressure deficit, which affects the transpiration from stomata, was highest in the late dry season. Therefore, we surmised that the transpiration peak appeared in the late dry season as a result of the combination of abundant soil moisture and a high vapor pressure deficit. Moreover, the peak of evapotranspiration corresponded to the foliation of evergreen species that occurred mainly at the beginning and near the end of the dry season. Figure 5 shows the relationships between rainfall, throughfall,

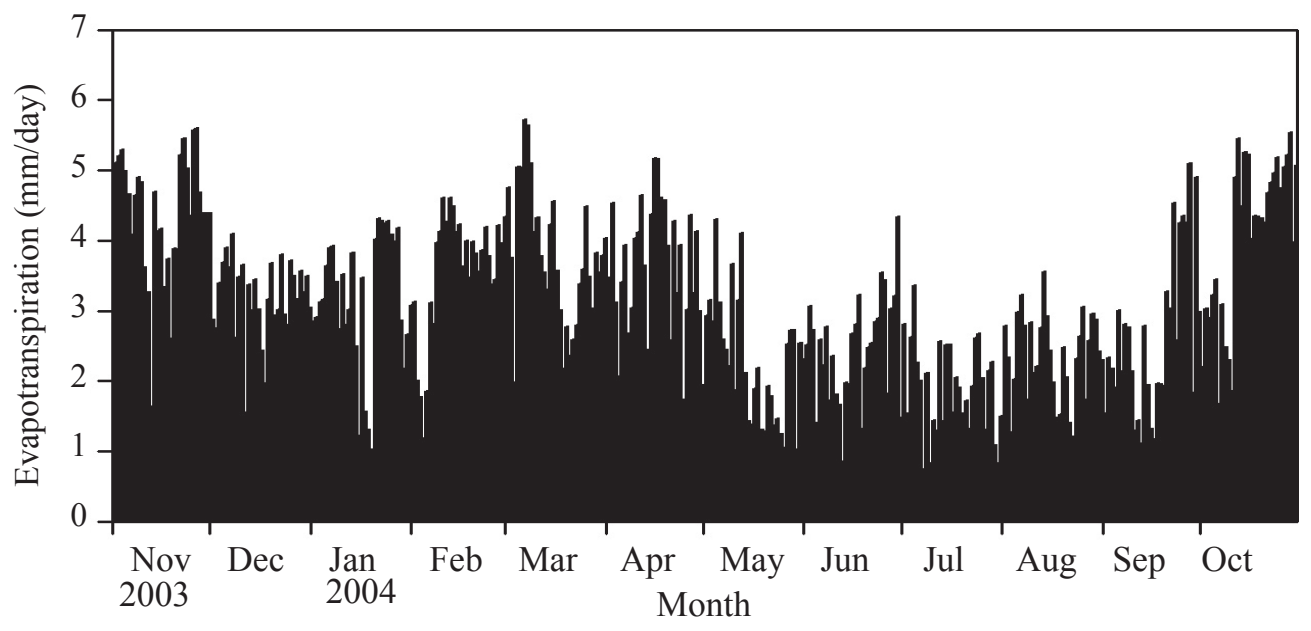

Fig. 4. Seasonal variation in daily evapotranspiration rate

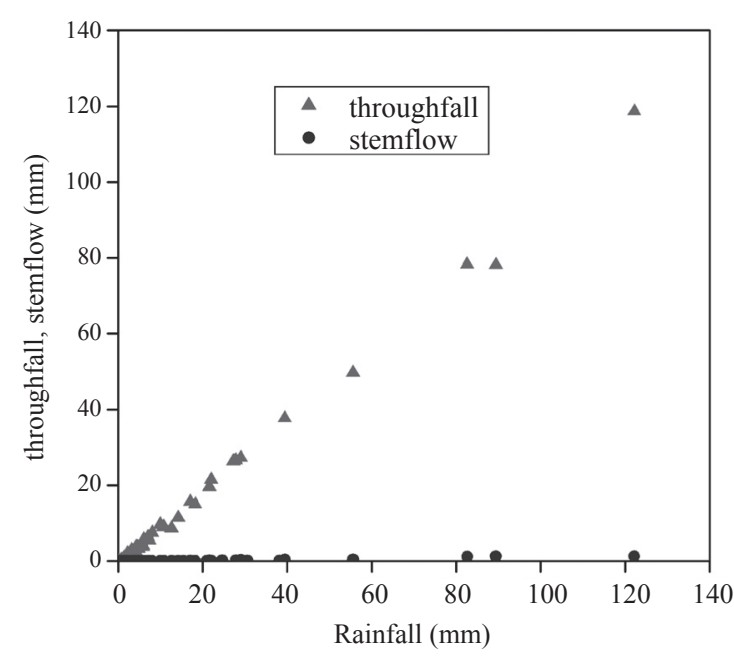

Fig. 5. Relationship between rainfall, throughfall and stem flow

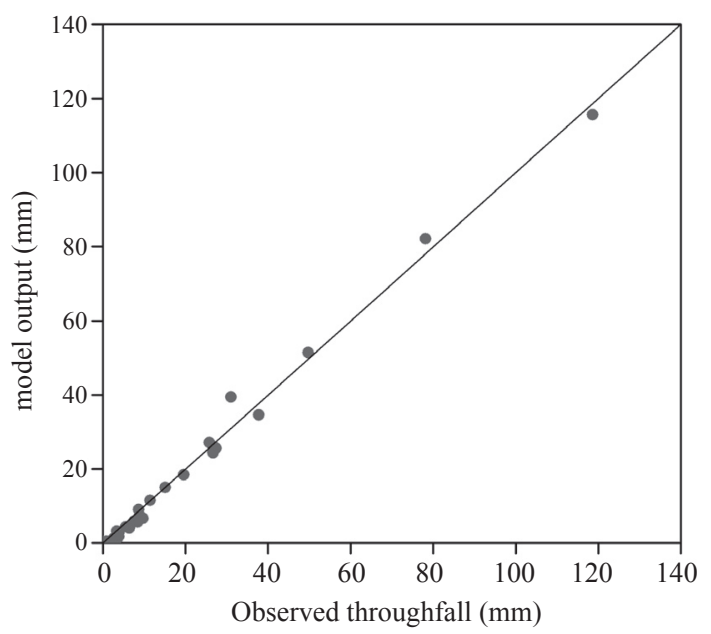

Fig. 6. Relationship between observed and simulated throughfall 


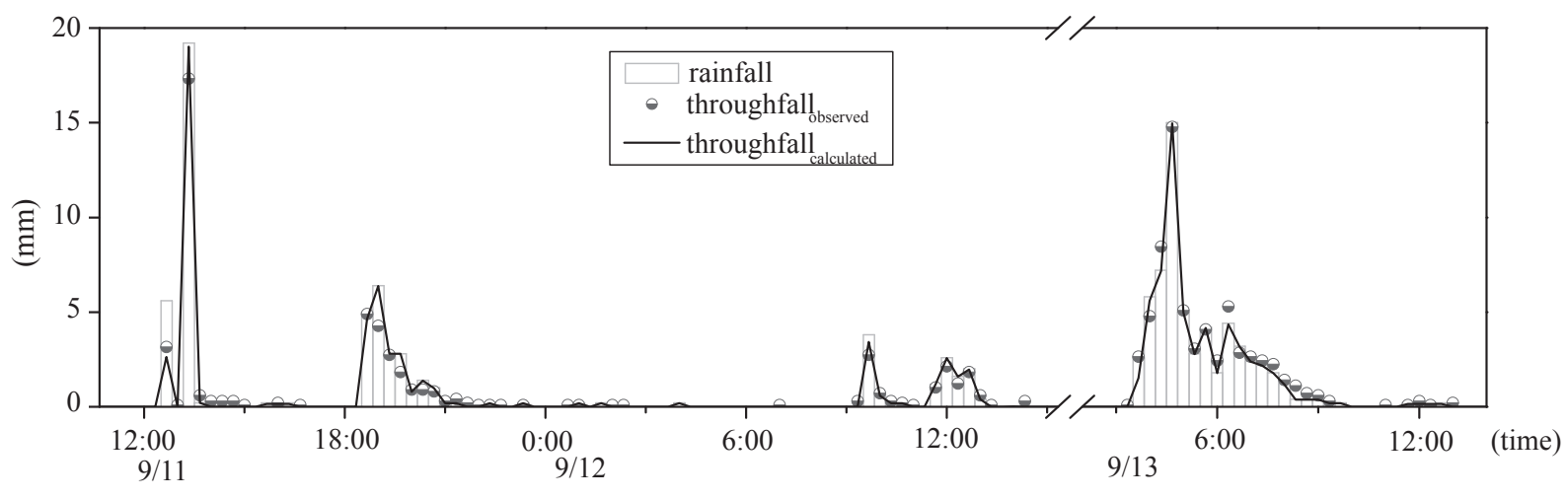

Fig. 7. Temporal variation in rainfall, observed throughfall and simulated throughfall

and stem flow in each rainfall event. Observational data of rainfall, throughfall, and stem flow indicated that the annual canopy interception rate was approximately $15 \%$.

For the purpose of factorial analysis of canopy interception, parameters of the multilayer model were examined using rainfall and meteorological observation data. Figure 6 shows time series of rainfall and observed and simulated throughfall during a large rainfall event (11-13 September 2004, rainfall total of $122.2 \mathrm{~mm}$ ). When the observed throughfall value was compared to the estimated value, both the time change and peak values coincided in most cases. Moreover, their variation corresponded to the variation in rainfall. Figure 7 shows the relationship between observed and simulated throughfall integrated for each rainfall event. For the most part, estimated throughfall coincided with the observed value. These results suggest that the temporal variation and the quantity of the output value by the multilayer model appropriately agreed well with the observed results. Examination of the sensitivity of model parameters suggested that water storage capacity of leaf surfaces and the seasonal variation in LAI strongly contribute to the canopy interception process.

These results are very useful as verification data based on the on-site continuous observation for the following estimation of the potential water-resources according to the large-scale model. This area had been an observational gap region where the actual condition of the water cycle in a forested watershed was completely unidentified in the Mekong River basin for a long time. According to this research project, the integrated observation site with regard to the water cycle was established in an evergreen forest watershed, and the long-term continuous observation system which can trace yearly fluctuation has been built. These observation results contribute to the various data utilization such as verification of model estimation, impact evaluation of selective logging, degradation, deforestation, and others.

\section{(2) Large scale model estimation of available renewable freshwater resources in forest areas of the Mekong River basin}

Plant phenology is affected by thermal conditions and water availability. We express the effect of thermal conditions on plant phenology using $\alpha$, which is parameterized in Japan $\left(\right.$ Sawano $\left.^{13}\right)$ as follows:

$$
a=0.0129 \times T+0.296
$$

where $\mathrm{T}$ is monthly temperature. Forest canopy moisture status is a consequence of water availability in the forested area $\left(\mathrm{Kume}^{7}\right)$. A shortage of water in the soil during the dry season affects transpiration activity. We used NDII data to evaluate the effect of a reduction in the soil water content on transpiration. The Normalized Difference Infrared Index (NDII) is a satellite-based index for measuring vegetation water content using a combination of short-wavelength infrared (SWIR) and near infrared (NIR) bands and the equation of Hunt and Rock ${ }^{5}$ : NDII=(NIRSWIR)/(NIR+SWIR). We used temporal series SPOTVEGETATION NDII data from 1998 to 2003 for forested areas to model the relationship between forest canopy moisture state and transpiration activity. We determined the relationship between NDII data and transpiration activity $^{7}$ and expressed it as follows:

$$
\begin{aligned}
& \alpha^{\prime}=\alpha \mathrm{F}(\mathrm{NDII}) \quad \mathrm{F}(\mathrm{NDII})=1, \underline{\text { when }} 0.18<\mathrm{NDII} \\
& \mathrm{F}(\mathrm{NDII})=5.5 \mathrm{NDII}+0.01, \underline{\text { when }} 0<\mathrm{NDII}<0.18 \\
& \mathrm{~F}(\mathrm{NDII})=0.01, \underline{\text { when }} \mathrm{NDII}<0
\end{aligned}
$$

The distribution of estimated evapotranspiration is shown in Fig. 6(a). Estimated evapotranspiration ranged from $180 \mathrm{~mm} /$ year in the upper basin to $1,400 \mathrm{~mm} /$ year in the lower basin, except at the water surface. Evapotranspiration rates ranging from 700 to $1,000 \mathrm{~mm} /$ year were widely distributed, and rates over $1,000 \mathrm{~mm} /$ year were distributed in the southern part of the basin. Higher rates of evapotranspiration, excluding water surfaces, were ob- 


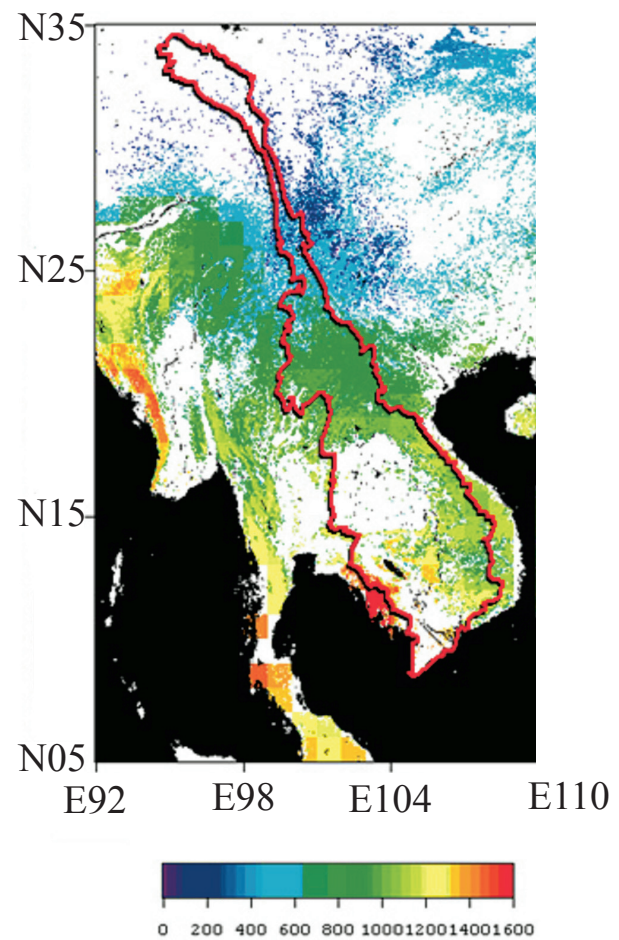

a) Evapotranspiration ( $\mathrm{mm} /$ year)

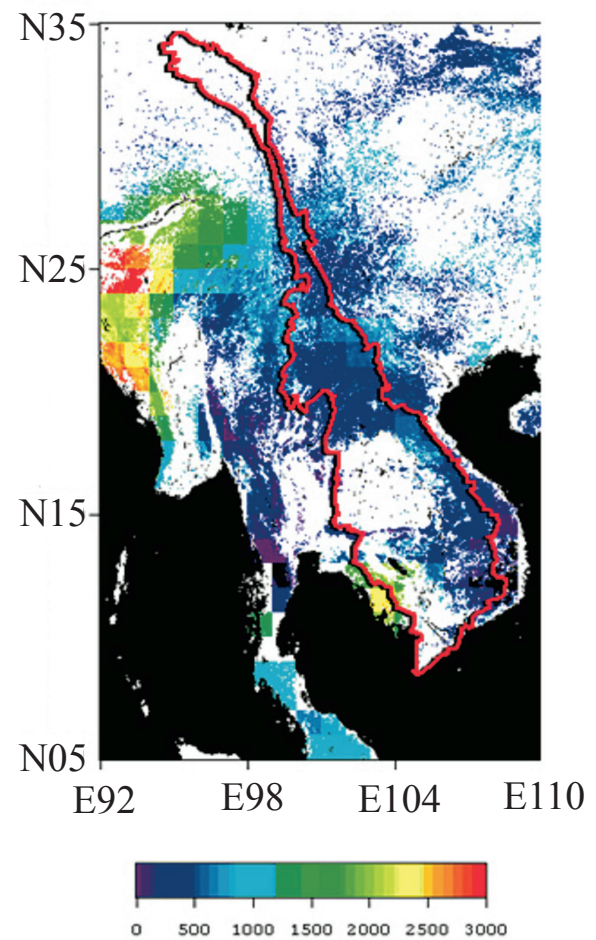

b) Available renewable freshwater resources (mm/year)

Fig. 8. a) Evapotranspiration and b) available renewable freshwater resources in the forested area in the Mekong River basin

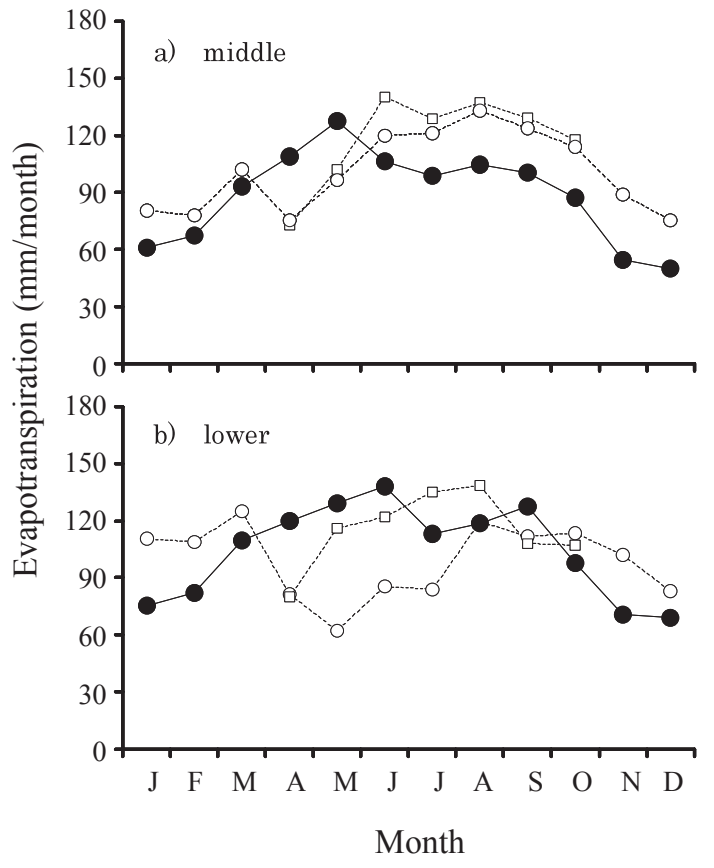

Fig. 9. Comparison of evapotranspiration from this study, ISLSCP and GAME-reanalysis data

a): Middle basin, b): Lower basin. We extracted an evergreen forest pixel (30-arcsec) from the same area as both the ISLSCP and GAME-reanalysis data for comparison.

$\bigcirc$ : ISLSCP, $\square$ : Game-reanalysis, $\bullet$ : estimated. served in western Cambodia.

Figure 7 provides a comparison between estimated evapotranspiration and latent heat flux in International Satellite Land Surface Climatology Project (ISLSCP) and GEWEX Asian_Monsoon Experiment (GAME) reanalysis data to validate model performance. We compared values in the middle and lower parts of the basin, where climatic zones and water availability differed significantly and covered mainly forested area. In the middle of the basin, the values estimated by our model had similar seasonal trends as with the ISLSCP and GAME reanalysis data. On the whole, our model estimates were lower than in the ISLS$\mathrm{CP}$ and GAME reanalysis data, but the high values were marked near the end of dry season. In the lower part of the basin, both our model estimates and the GAME reanalysis data showed a middle rainy season peak, but the ISLSCP data differed from our model in seasonal trend.

Figure 6(b) shows the distribution of annual available RFWR in a forested area of the Mekong. Annual available RFWR in these forest landscapes are distributed from 300 to $2,200 \mathrm{~mm} /$ year. An area with ample RFWR is the mountainous area in western Cambodia, and almost all regions have $500 \mathrm{~mm} /$ year. This result mostly corresponded to the amount of water resources of about $350 \mathrm{~mm}$ in the largest evergreen forest experimental watershed including 
several small watersheds with 100 to $550 \mathrm{~mm}$ discharge in central Cambodia. Consequently, this large scale model is considered to be available in future prediction of waterresources fluctuation. Hereafter, it is necessary to carry out the improvement in the estimated precision in the whole basin, the modification of the parameter estimation procedure corresponding to the grid size of the model in order to perform practical and highly precise prediction.

\section{Acknowledgments}

This study was funded by the "Assessment of the Impact of Global-Scale Change in Water Cycles on Food Production and Alternative Policy Scenario (2003-2007)" of AFFRCS (Agriculture, Forestry, and Fisheries Research Council Secretariat), Japan. The multilayer model used for calculation was developed by Dr. Tanaka in Research Institute for Global Change, JAMSTEC.

\section{References}

1. Calder, I. R. (1986) A study of evapotranspiration from tropical rain forest-West Java., J. Hydrol., 89, 13-31.

2. Hansen, M. C. et al. (2000) Global land cover classification at $1 \mathrm{~km}$ spatial resolution using a classification tree approach., Int. J. Remote Sens., 21(6-7), 1331-1364.

3. Hayashi, Y. et al. (1989) Spacial distribution of actual evapotranspiration rate in Northeast Thailand during the dry season., JARQ, 22(4), 260-267.

4. Hori, H. (1996) The Mekong: the development and its environmental effects. KOKON-SHOIN Publishing, Tokyo, Japan, pp.476.

5. Hunt, Jr. E. R., \& Rock, B. N. (1989) Detection of changes in leaf water content using near and middle-infrared reflectances., Remote Sensing of Environment, 30, 43-54.

6. Komatsu, H. et al. (2007) Seasonal trends in the solar radiation/net radiation ratio above a Cryptomeria japonica plantation forest. Bulletin of Tokyo University Forest, 117,
$11-19$.

7. Kume, T. et al. (2007) Impact of soil drought on sap flow and water status of evergreen trees in a tropical monsoon forest in northern Thailand. Forest Ecology and Management, 238(1-3), 220-230.

8. Meeson, B. W. et al. (1995) ISLSCP Initiative 1. Global data sets for land-atmosphere models, 1987-1988., Published on CD-ROM by NASA. (USA_NASA_GDAAAC ISLSCP_001.-USA_NASA_GDAAC__ISLSCP_005).

9. Narith, $\bar{H}$. (1997) Asia-Pacific forestry sector outlook study: Country paper on some aspects of forestry in Cambodia., APFSOS/WP/18, Food and Agriculture Organization of the United Nations.

10. Nobuhiro, T. et al. (2007) Year-round observation of evapotranspiration in an evergreen broadleaf forest in Cambodia. In Forest environments in the Mekong River basin., eds. Sawada, H. et al., Springer, Tokyo, Japan, 75-86.

11. Ohta, S. et al. (2004) Forest and its properties in Kampong Thom, Cambodia. In Proceedings of the international workshop on forest watershed 2004, eds. Sawada, H. et al., Forestry and Forest Research Institute and Forestry Administration, Japan, 20-23.

12. Priestley, C. H. B. \& Taylor, R. J. (1972) On the assessment of surface heat flux and evaporation using large-scale parameters. Month. Weather Rev., 100, 81-92.

13. Sawano, S. (2003) Simple model for evaluating the evapotranspiration of a forested area in Japan. M. S. thesis, University of Tokyo, Japan [In Japanese].

14. Tanaka, K. et al. (2003) Transpiration peak over a hill evergreen forest in northern Thailand in the late dry season: Assessing the seasonal changes in evapotranspiration using a multilayer model., J. Geophys. Res., 108(D17), 4533. DOI: 10.1029/2002JD003028.

15. Yatagai, A. et al. (2000) About GAME reanalysis data., J. Jpn. Soc. Hydrol. Water Resour., 13(6), 486-495 [In Japanese].

16. Yoshifuji, N. et al. (2007) Factors affecting interannual variability in transpiration in a tropical seasonal forest in Northern Thailand: Growing season length and soil drought. In Forest environments in the Mekong River basin., eds. Sawada, H. et al., Springer, Tokyo, Japan, 56-66. 